\title{
Title: Integration of In-Situ Resource Utilization Into Lunar/Mars Exploration Through Field Analogs
}

\author{
Gerald B. Sanders ${ }^{1}$, William E. Larson ${ }^{2}$ \\ ${ }^{1}$ NASA Johnson Space Center, 2101 NASA Parkway, Houston, TX 77058, USA \\ 281-483-9066, gerald.b.sanders@nasa.gov \\ ${ }^{2}$ NASA Kennedy Space Center, Kennedy Space Center, Florida 32899, USA \\ 321-867-8747, william.e.larson@nasa.gov
}

\begin{abstract}
The NASA project to develop In-Situ Resource Utilization (ISRU) technologies, in partnership with commercial and international collaborators, has achieved full system demonstrations of oxygen production using native regolith simulants. These demonstrations included robotic extraction of material from the terrain, sealed encapsulation of material in a pressurized reactor, chemical extraction of oxygen from the material in the form of water, and the electrolysis of water into oxygen and hydrogen for storage and reuse. These successes have provided growing confidence in the prospects of ISRU oxygen production as a credible source for critical mission consumables in preparation for and during crewed missions to the moon and other destinations. Other ISRU processes, especially relevant to early lunar exploration scenarios, have also been shown to be practical, including the extraction of subsurface volatiles, especially water, and the thermal processing of surface materials for civil engineering uses and for thermal energy storage. This paper describes these recent achievements and current NASA ISRU development and demonstration activity. The ability to extract and process resources at the site of exploration into useful products such as propellants, life support and power system consumables, and radiation and rocket exhaust plume debris shielding, known as In-Situ Resource Utilization or ISRU, has the potential to significantly reduce the launch mass, risk, and cost of robotic and human exploration of space. The incorporation of ISRU into missions can also significantly influence technology selection and system development in other areas such as power, life support, and propulsion. For example, the ability to extract or produce large amounts of oxygen and/or water in-situ could minimize the need to completely close life support air and water processing system cycles, change thermal and radiation protection of habitats, and influence propellant selection for ascent vehicles and surface propulsive hoppers. While concepts and even laboratory work on evaluating and developing ISRU techniques such as oxygen extraction from lunar regolith have been going on since before the Apollo 11 Moon landing, no ISRU system has ever flown in space, and only recently have ISRU technologies been developed at a scale and at a system level that is relevant to actual robotic and human mission applications. Because ISRU hardware and systems have never been demonstrated or utilized before on robotic or human missions, architecture and mission planners and surface system hardware developers are hesitant to rely on ISRU products and services that are critical to mission and system implementation success. To build confidence in ISRU systems for future missions and assess how ISRU systems can best influence and integrate with other surface system elements, NASA, with international partners, are performing analog field tests to understand how to take advantage of ISRU capabilities and benefits with the minimum of risk associated with introducing this game-changing approach to exploration. This paper will describe and review the results of four analog field tests (Moses Lake in 6/08, Mauna Kea in 11/08, Flagstaff in 9/09, and Mauna Kea in $1 / 10$ ) that have begun the process of integrating ISRU into robotic and human exploration systems and missions, and propose future ISRU-related analog field test activities that can be performed in collaboration with international space agencies.
\end{abstract}


ISRU involves any hardware or operation that harnesses and utilizes 'in-situ' resources (natural \& discarded) to create products and services for robotic and human exploration

Five Major Areas of ISRU

Resource Characterization and Mapping

Physical, mineral/chemical, and volatile/water
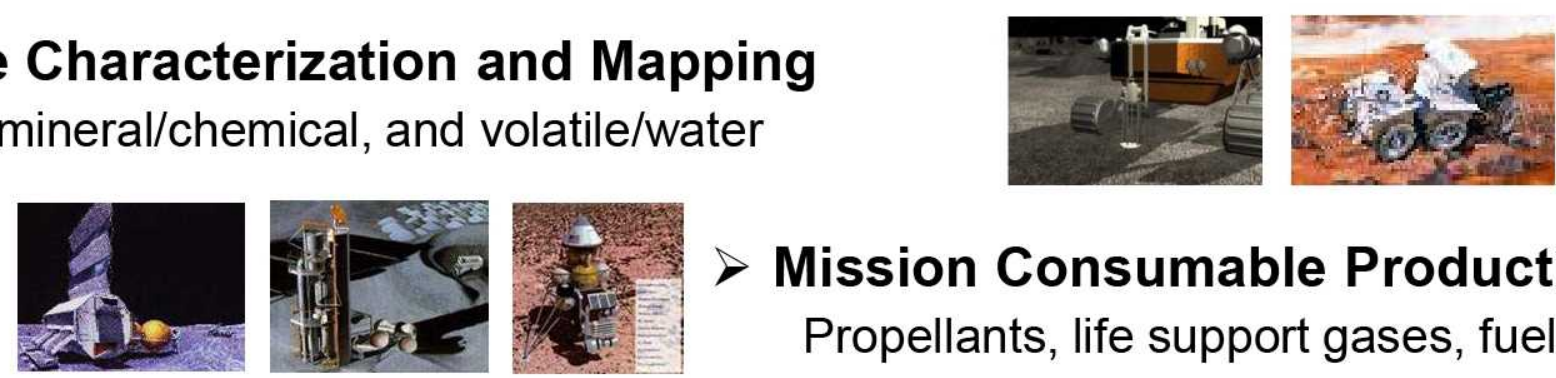

$>$ Mission Consumable Production

Propellants, life support gases, fuel cell reactants, etc.

\section{Civil Engineering \& Surface Construction}

Radiation shields, landing pads, roads, habitats, etc.
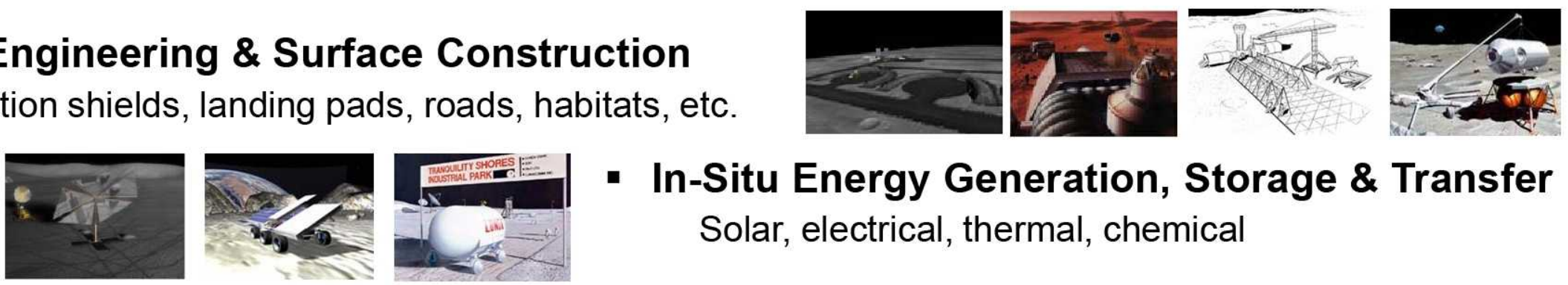

- In-Situ Energy Generation, Storage \& Transfer Solar, electrical, thermal, chemical

- In-Situ Manufacturing \& Repair

Spare parts, wires, trusses, integrated structures, etc.
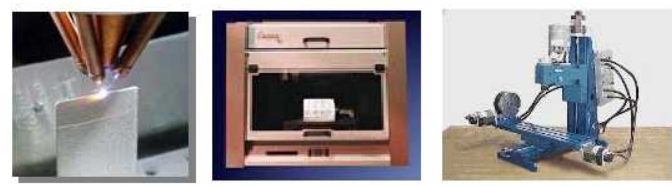

$>$ 'ISRU' is a capability involving multiple technical discipline elements (mobility, regolith manipulation, regolith processing, reagent processing, product storage \& delivery, power, manufacturing, etc.)

$>$ 'ISRU' does not exist on its own. By definition it must connect and tie to multiple uses and systems to produce the desired capabilities and products. 


\section{ISRU: Critical for Affordable, Flexible, \& Sustainable Exploration}

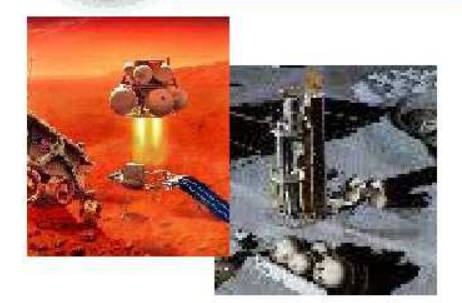

Propellant Production

- Reduces Earth to orbit mass by 20 to $\mathbf{4 5 \%}$ for Mars missions

- 3.5:1 to 5:1 mass savings leverage from Moon/Mars surface back to Low Earth Orbit

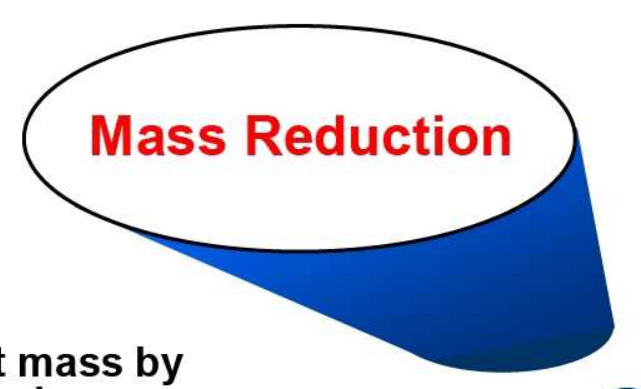

\section{Space}

Resource

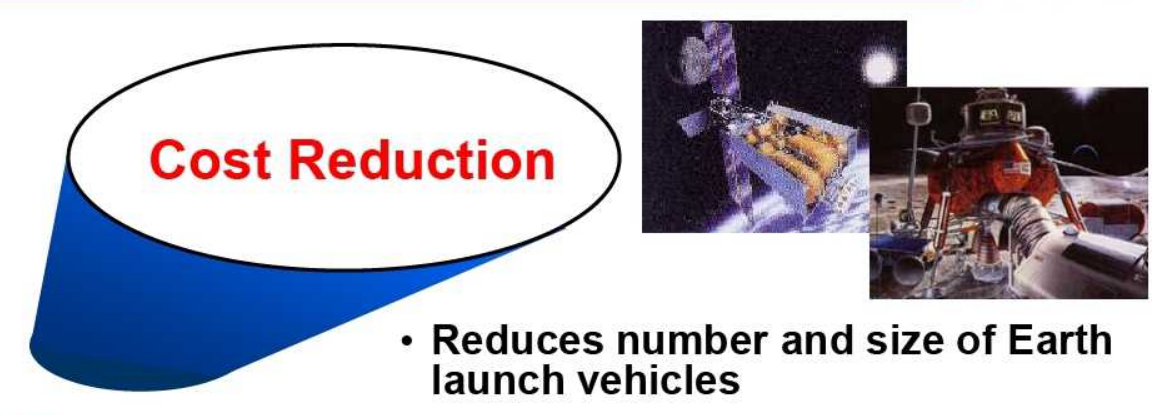

- Allows reuse of transportation assets

- Minimizes development costs

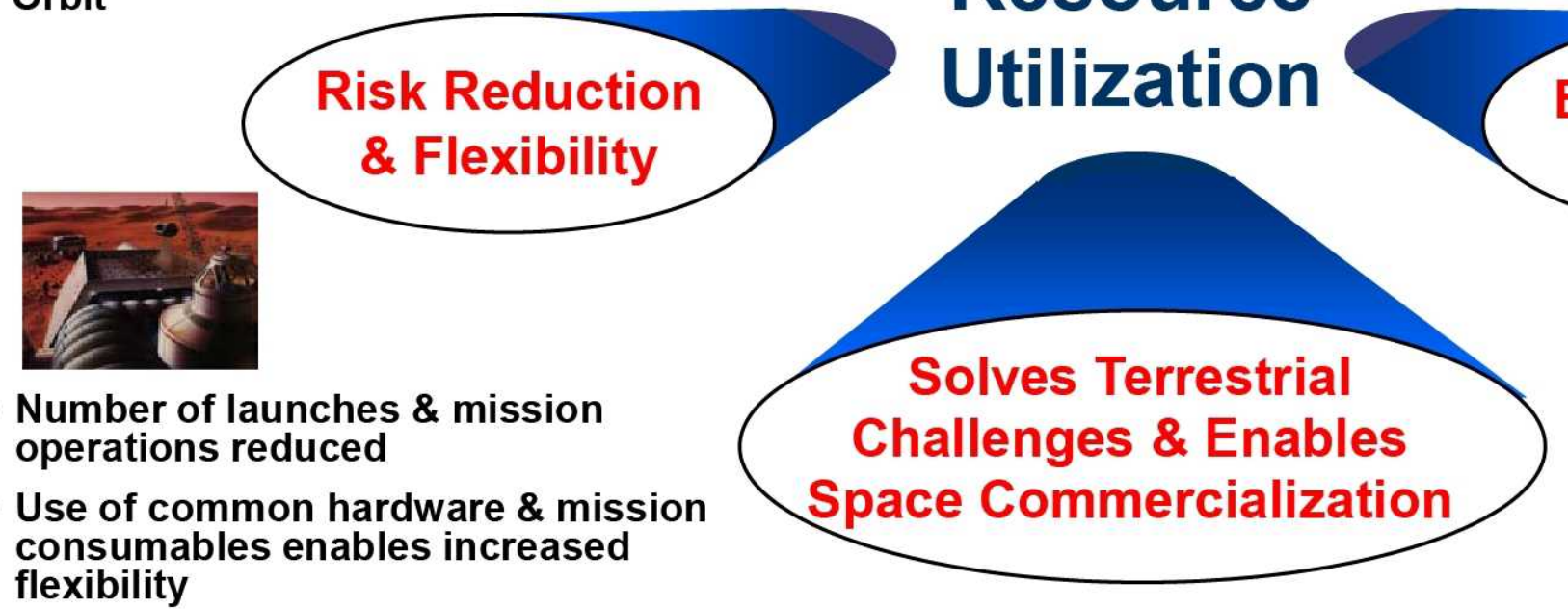

- In-situ fabrication of spare parts enables sustainability and selfsufficiency

- ISRU can provide dissimilar redundancy

- Radiation \& Plume Shielding

- Reduces dependence on Earth
- Develops alternative \& renewable energy technologies

- $\mathrm{CO}_{2}$ remediation

- Green metal production
Provides infrastructure to support space commercialization

- Propellant/consumable depots at Earth-Moon L1 \& Surface for Human exploration \& commercial activities

\section{Expands Human} Presence

- Increase Surface Mobility \& extends missions

- Habitat \& infrastructure construction

- Propellants, life support, power, etc.

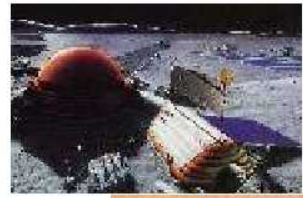

- Substitutes sustainable infrastructure cargo for propellant $\&$ consumable mass

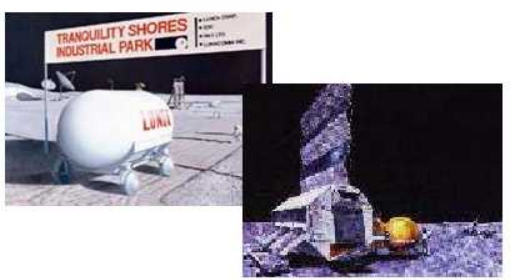




\section{Key Architecture Decisions That Impact ISRU}

- Is Abort-to-Surface (vs Abort-to-Orbit) a Viable Option? If yes:

- Ascent propellant production and transfer to increase payload to surface is possible

- Is Reusable Transportation (even one reuse) a Long-term Objective? If yes:

- Landing/ascent pads and surface propellant depots

- Large scale propellant production

- If $\mathrm{O}_{2} / \mathrm{H}_{2}$ propellants -> Need polar water or $\mathrm{H}_{2}$ delivery from Earth

- If $\mathrm{O}_{2} / \mathrm{CH}_{4}$ propellants $->\mathrm{Need} \mathrm{O}_{2}$ from regolith and $\mathrm{CH}_{4}$ from trash/waste/plants or $\mathrm{CH}_{4}$ delivery from Earth

- Propellant depots in LLO or $\mathrm{L}_{1}$

- Surface hopping to other locations (and back)

- How Much Radiation Shielding is Adequate for Crew Protection?

- Propellant scavenging for water/hydrogen

- Habitat burial or regolith shielding of habitats

- Trash processing for radiation shielding

- What is the approach for eclipse/night survival and operation ?

- Increased fuel cell reactant storage

- Thermal storage with in-situ materials ('wadis')

- Is Mars Forward the Primary Goal for Lunar Exploration?

- Demonstrate Mars applicable technologies, systems, and applications

- Demonstrate remote/uncrewed and long-duration operations

- Is Space Commercialization and Long-term Settlement of the Moon a Goal?

- In-situ fabrication, construction, power, and consumables by commercial provider 


\section{ISRU Connectivity with Other Exploration Elements Strongly Influences Designs}

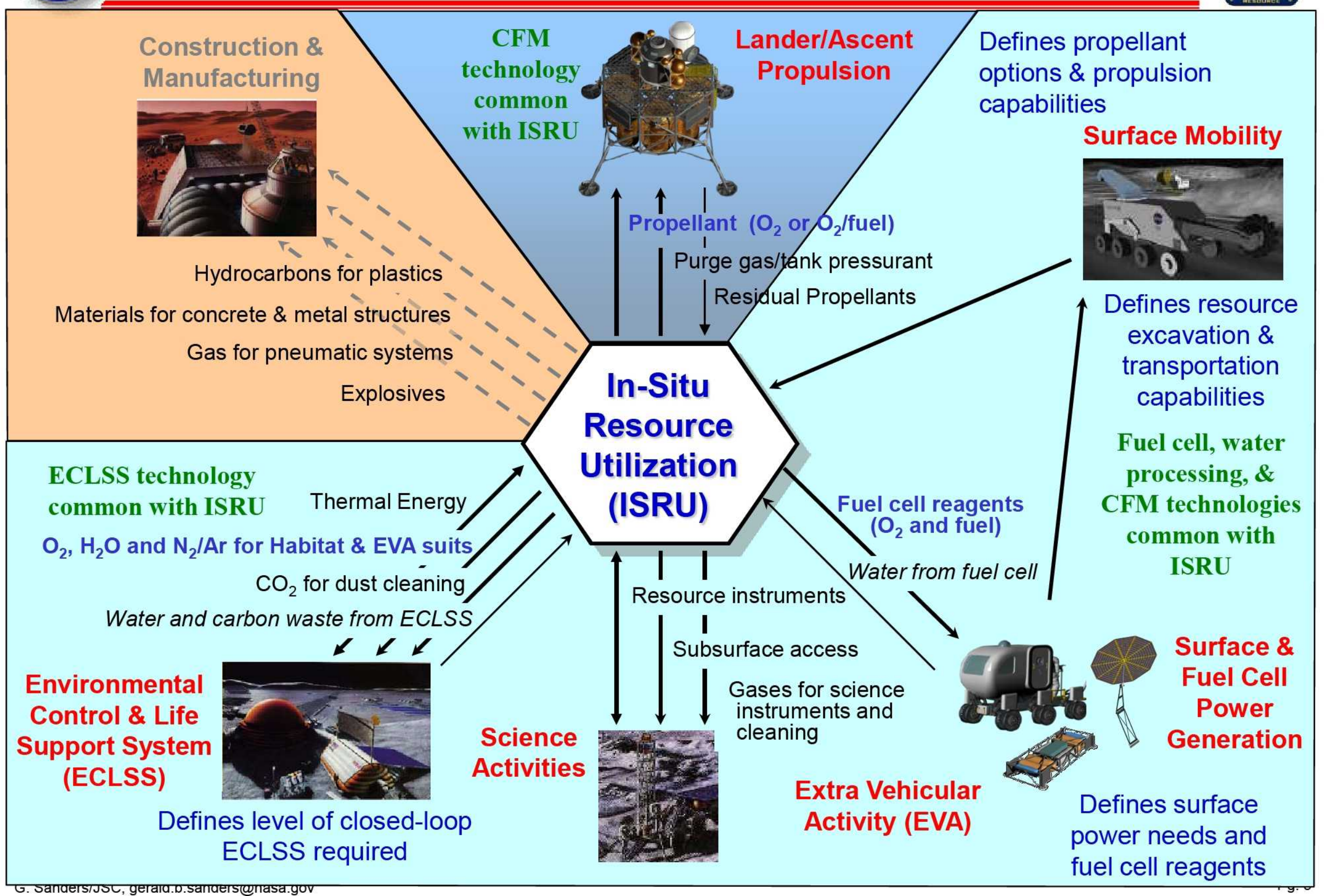




\section{ISRU Development \& Operation Challenges}

Maximize benefit of using resources, in the shortest amount of time, while minimizing crew involvement and Earth delivered infrastructure

- Resource knowledge

- Characterization of form and spatial distribution of resources to degree necessary to plan use of ISRU at possible sites of exploration

- Operation in severe environments

- Operation and interaction with dust

- Efficient excavation of resources in extremely cold, vacuum, and/or micro-g environments

- Startup/shutdown cycles during day/night

- Methods to mitigate dust/filtration for Mars atmospheric processing

- Long-duration, remote and autonomous operation

- Autonomous control \& failure recovery

- Long-duration operation (>300 days for Mars; 3 years for lunar)

- High reliability and minimum (zero) maintenance

- High reliability due to no (or minimal) maintenance capability for pre-deployed and robotic mission applications

- Failure mitigation approach

- Development of highly reliable thermal/mechanical cycle units

- Development of highly reliable, autonomous calibration control hardware and sensors

- Integrated fluids and operations with other Elements

- Interfaces and standards

- Common fluids and hardware 


\section{Problem with Incorporation of ISRU into Missions}

- ISRU incorporated into human exploration missions is a conundrum

$\longrightarrow>$ Learning to use the resources at the site of exploration (ISRU) to reduce cost and risk is considered an important part of why we are exploring space

$>$ However, since ISRU has never been flown/demonstrated, mission planners do not want to rely on ISRU for mission success

$>$ Architectures and elements that do not rely on ISRU are designed differently and benefits downstream are greatly reduced (ex. ELS and Lander Propulsion)

$>$ Therefore, ISRU is not 'Critical' for the architecture and implementation is delayed, BUT ...

Early ISRU

Validation Thru Precursors
Earlier ISRU $=$ Incorporation and $=$ Use in Missions
Greater cost \& risk reduction; Earlier

Sustainability

- Two possible approaches to break the "Catch 22" cycle

- Fly ISRU demonstrations on robotic precursor missions to validate environmental compatibility and performance capability

* Perform integrated ground tests of ISRU with linked surface and transportation systems to validate interfaces and product availability and quality 


\section{Why Perform Analog Field Tests?}

Concrete Benefits of Field/Analog Testing

- Mature Technology

- Evaluate Mission Architecture Concepts Under Applicable Conditions

- Evaluate Operations \& Procedures

- Integrate and Test Hardware from Multiple Organizations

- Develop engineers and project managers

Intrinsic Benefits of Field/Analog Testing

- Develop International Partnerships

- Develop Teams and Trust Early

- Develop Data Exchange \& Interactions with International Partners (ITAR)

- Outreach and Public Education 


\section{Early Surface Preparation Field Evaluation}

- Mosses Lake, June 2008: LANCE Blade mounted to "Chariot" mobile platform

- $1^{\text {st }}$ integrated field test of ISRU hardware on mobility platform for surface construction

- No articulation capability on blade required mobile platform to perform all $x-y-z$ actuations

- Large area cleared and berm built via on-site, visual tele-operation

- Blade interference with ground on rough terrain due to extension from front end
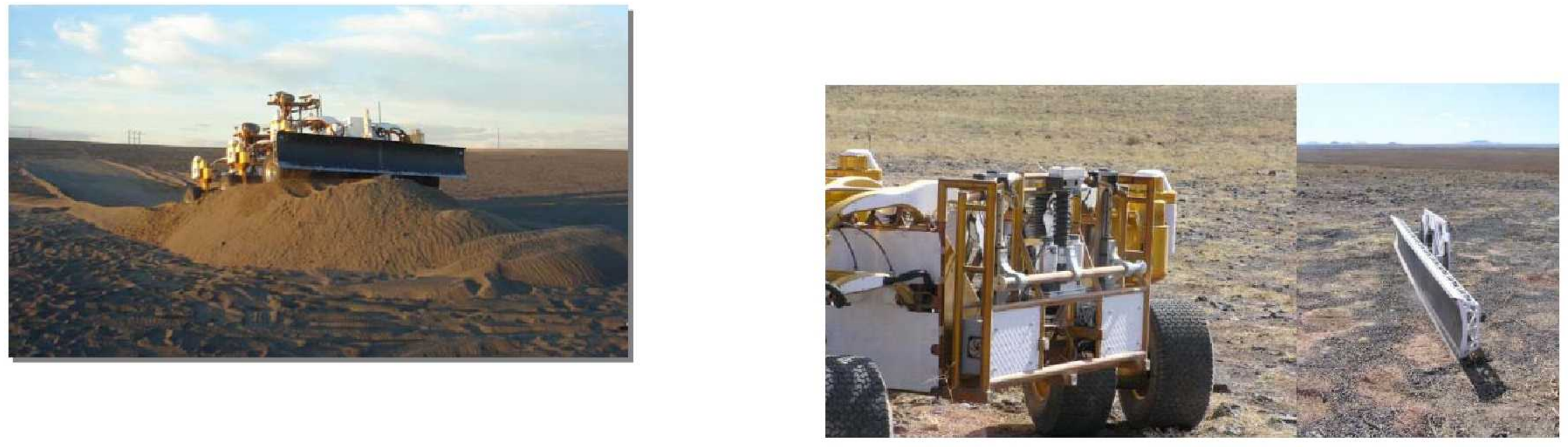

- Flagstaff, Sept. 2009: LANCE Blade mounted to "Chariot" \& LER platforms

- Z-axis articulation capability on blade allowed better ground clearance on rough terrain

- Quick disconnect mechanism allowed for blade integration and removal for dedicated tests

- Similar overall surface preparation performance 


\section{$1^{\text {st }}$ ISRU System Analog Field Test}

\section{Field Test Mission Objectives}

- Field Dates: Oct. 30 to Nov. 15, 2008

Location: Mauna Kea , Hawaii

- Mission Key Personnel

- Jerry Sanders \& Bill Larson, ISRU PM

- Rob Ambrose HRS PM \& John Caruso

- Tom Simon/OPTIMA lead

- Frank Schowengert, PISCES

- Jackie Quinn/RESOLVE lead

- Michel Doyon, CSA

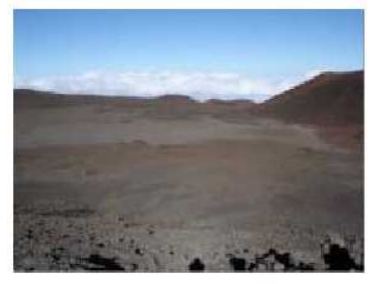

- Need for ISRU Field Test

$>$ Hardware from the ISRU Project needed to move from the laboratory to more challenging conditions

> ISRU Hardware had never operated in an end-to-end system before or had been field tested

- NASA Hardware-Operation Objectives

1. ISRU Mobile Resource Prospecting \& Oxygen Production Demo Field Test: Test resource prospecting, site survey, and oxygen production activities while integrated onto a mobile platform

2. ISRU End-to End Outpost Scale Oxygen Production \& Storage Field Test (OPTIMA): Demonstrated excavation, regolith delivery, regolith processing, and oxygen production and storage

3. Demonstrate partnership with State of Hawaii and Pacific International Space Center for Exploration Systems (PISCES): Have PISCES 'host' field test activity by providing support, logistics, and facilities

5 NASA Centers, 2 International Space Agencies, 7 Companies, \& 2 Universities 


\section{ISRU Hardware Tested at Analog Site}

\section{Lunar Prospecting}

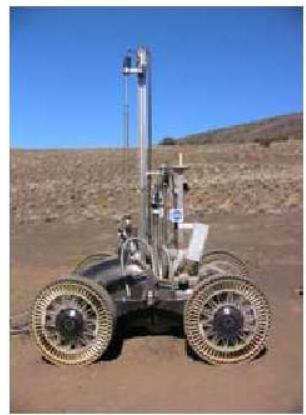

- Scarab Rover

- RESOLVE

- TriDAR Vision System

- Tweels
Outpost-Scale $\mathrm{O}_{2}$ from Regolith

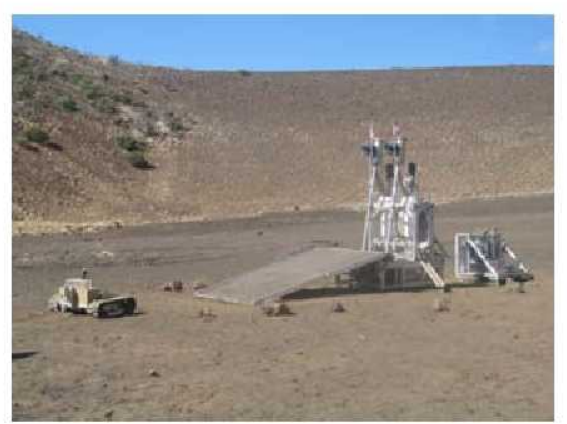

- ROxygen $\mathrm{H}_{2}$ Reduction

- Water Electrolysis

- Cratos Excavator

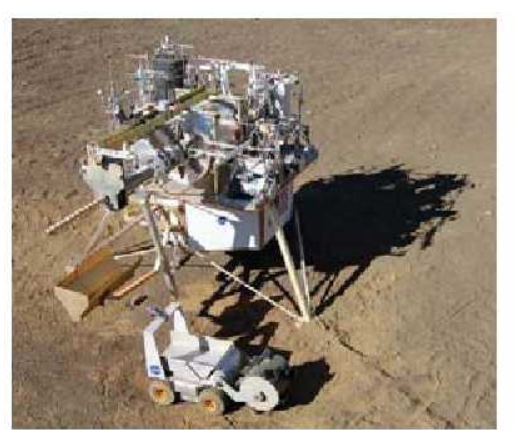

- PILOT $\mathrm{H}_{2}$ Reduction

- Water Electrolysis

- Bucketdrum Excavator
Process Control \& Science

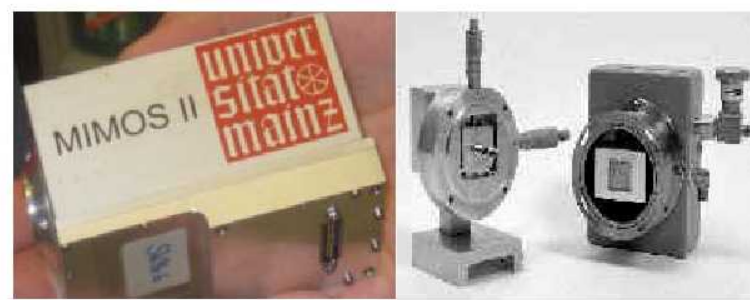

- Moessbauer

- Mini Chemin XRD/XRF

- Canadian Space Agency

- TriDAR imager, Satellite communications, remote operation of Drill and TriDAR navigation, and on-site personnel and payload mobility

- NORCAT, Xiphos, Argo, Virgin Technologies, EVC, Ontario Drive Gear, University of Toronto
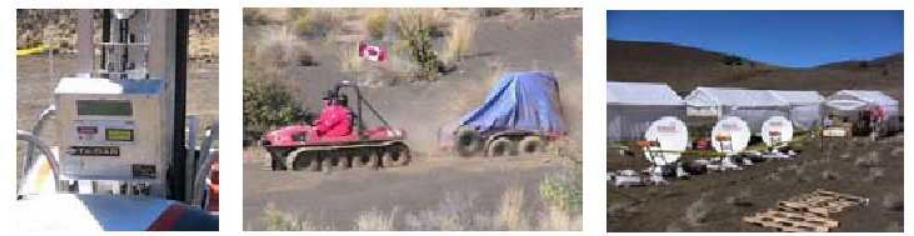

- German Space Agency (DLR)

- Instrumented "Mole" \& Sample Capture Mole

- Carnegie Mellon University - SCARAB Rover

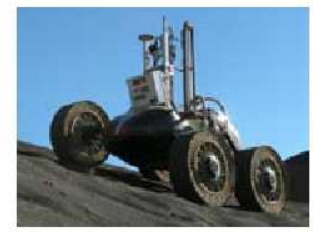

- JPL Partnership with Michelin on 'Tweels' testing
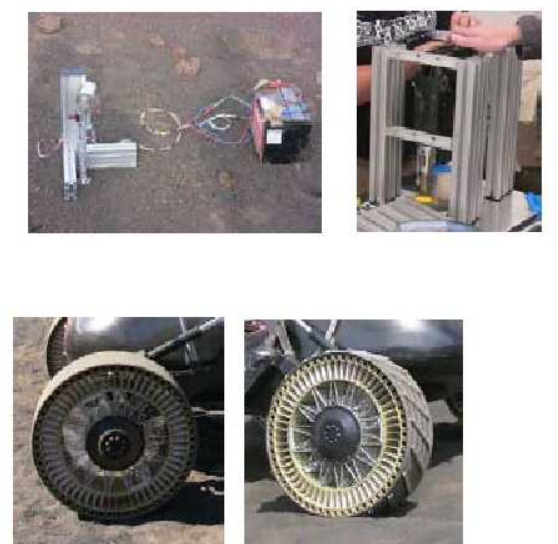


\section{Major Results From Nov. 2008 ISRU Analog Field Test}

$\square$ Demonstrated end-to-end operation of RESOLVE/Scarab; roving over varied terrain, dark navigation, drill site selection; remote operation from CSA

$\square$ Demonstrated end-to-end PILOT \& ROxygen operations: regolith delivery, reactor fill/empty, regolith processing, water capture and clean-up, oxygen production

घ RESOLVE: 6 Drilling, 6 Volatile characterization; and 4 Oxygen extraction operations

$\checkmark$ PILOT: 6 complete reactor operations; $1000 \mathrm{ml}$ of water produced from iron-oxide

$\square$ ROxygen: 5 complete reactor operations (2 Argon/3 Hydrogen)

$\square 1^{\text {st }}$ Successful field deployment of ISRU

- $1^{\text {st }}$ field deployment with International Partner 


\section{Field Test Mission Objectives}

- Field Dates: Jan. 24 - Feb. 14, 2010

Location: Mauna Kea , Hawaii

- Mission Key Personnel

- Jerry Sanders/Bill Larson/Janine Captain, ISRU - Dale Boucher, NORCAT

- Glen Bilodeau, CSA

- Frank Schowengardt/Bob Fox, PISCES

- Lutz Richter, DLR

- NASA Hardware-Operation Objectives

1. $\mathrm{O}_{2}$ Production from Regolith: Test enhanced Oxygen extraction from regolith system \& operations

2. ISRU Product Storage \& Utilization: Test hardware, operations, and energy systems that promote product usage

3. Lunar ISRU, Exploration, \& Science Integration: Integrate lunar exploration, resource \& site evaluation, and lunar science objectives, instruments, and operations

4. Site Preparation: Test hardware, operations, and surface sintering techniques

5. Field Geology Training: Train astronauts, ISRU, and NASA/CSA management on geology

8 System Modules - 7 Instruments

6 NASA Centers, 6 Small Businesses, 5 Universities

(42 people plus visitors)

12 System Modules \& Attachments; Infrastructure

3 Canadian Government Agencies, 8 Small Businesses, 2 Universities

(46 people plus visitors) 


\section{Major Results From Jan. 2010 ISRU Analog Field Test}

$\checkmark$ Extracted oxygen from local tephra (28 gms or $9.6 \%$ ave. yield) using advanced processing and regolith transfer hardware in end-to-end configuration

$\square$ Electrolyzed water from tephra and fuel cell, transferred oxygen to cryogenic cart for liquefaction, and performed $17 \mathrm{LO}_{2} / \mathrm{CH}_{4}$ thruster firings; "Dust to Thrust"

$\square$ Sintered two surface pads with two different methods and performed thruster firings with high speed camera to understand plume effects on unmodified and modified surfaces

$\square$ Integrated NASA and CSA/Canadian hardware in multiple critical applications

$\square$ Operated RESOLVE remotely from KSC and Solar Collector, Carbothermal Reactor, and Water Electrolysis systems remotely from JSC

$\square$ Tested SMD FSAT and MMAMA instruments for site/mineral characterization and support oxygen extraction process evaluation

$\square$ Completed field geology training with NASA and CSA managers and a CSA astronaut 


\section{Potential Areas of Interest for Next Analog Test}

\section{Scout \& Prepare for Human Mission}

Scout Terrain \& Resource

\section{Cache Consumables with ISRU}

\section{Prepare Site \& Power System}

Crew Arrives

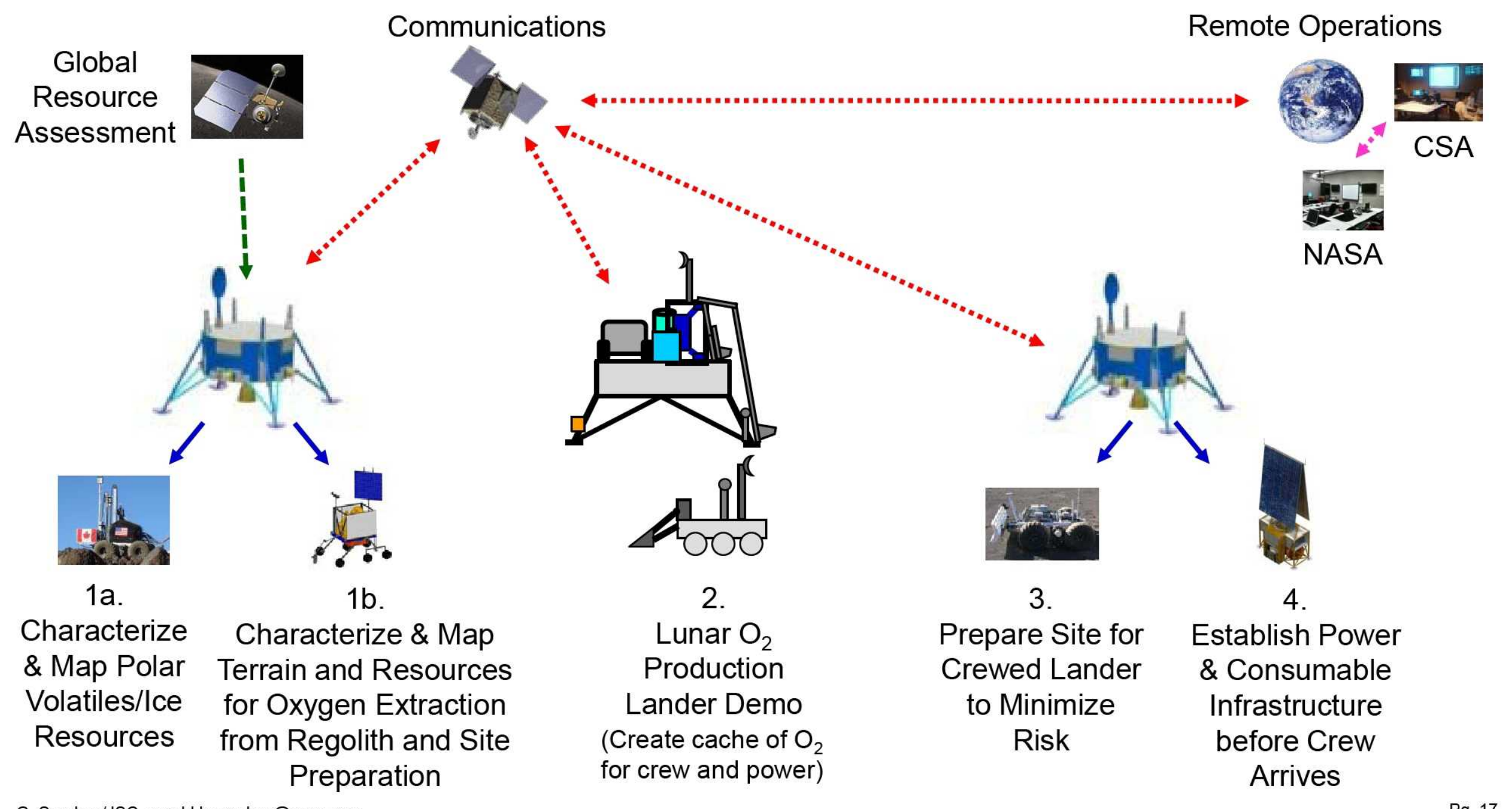




\section{Backup}




\section{ISRU Enables Sustainable \& Affordable Transportation \& Surface Exploration}

$3.5: 1$ to $>5: 1$ mass savings leverage from surface back to Low Earth Orbit

* $>70 \%$ of LSAM mass is propellant

* $>35 \%$ of landed payload mass is propellant for ascent vehicle

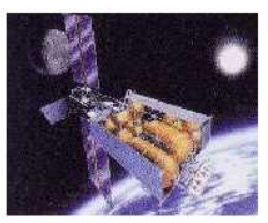

Oxygen, Water, \& Propellant from Lunar ISRU

Propellant Depot for:

- Lunar ascent/descent

- Trans-Earth Injection

- Other destinations

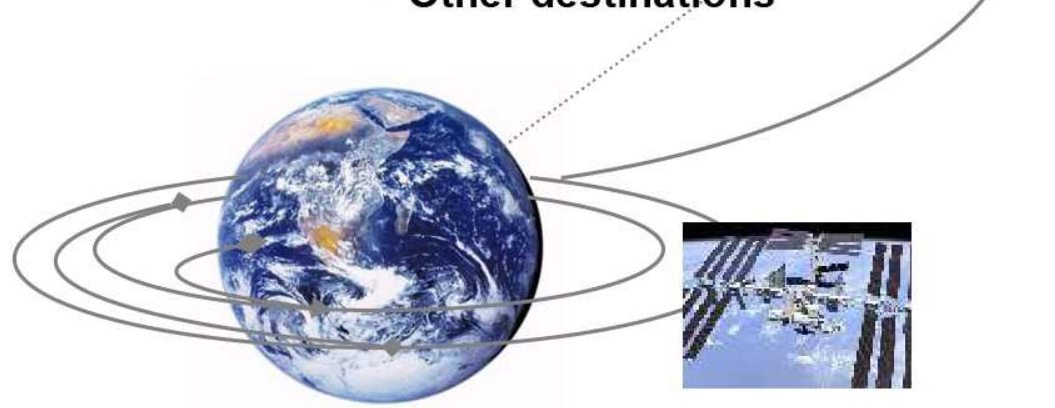

Earth Orbit Operations
Lunar Surface

Earth-Moon Staging Point

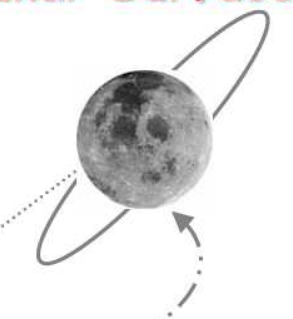

Lander \& Hopper Propellant Resupply \& Servicing for Reuse

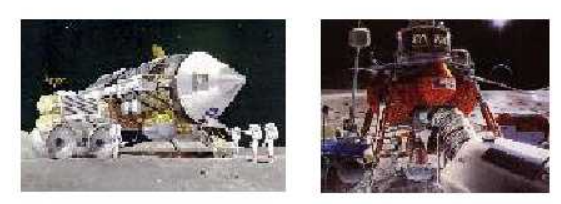

e

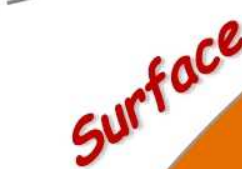

Common ISRU-provided consumables for Propulsion, EVA \& Habitat Life Support, and EVA Suit \& Rover Power

\section{Shielding for Radiation \&}

Dust/Plume Protection

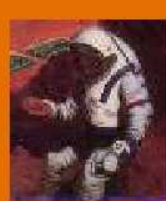

$\checkmark$ Reduces Earth launch mass and cost or increases payload delivery capability

$\checkmark$ Maximizes ability to reuse transportation assets further reducing cost

$\checkmark$ Minimizes risk due to functional backup and flexibility in recovering from failures

$\checkmark$ Increased surface mobility and power-rich environment enables new science and exploration capabilities 


\section{Incorporation of ISRU can strongly effect requirements and hardware/technology options selected}

\begin{tabular}{|l|l|}
\hline \multicolumn{2}{|c|}{ Requirement Connectivity } \\
\hline Propulsion Systems & Propellant Quanity \\
& Propellant Type \\
& Residual Amount \\
& Storage Capability \\
\hline Life Support/EVA Systems & Consumable Quantity \\
& Consumable Type \\
& Waste Products/Trash \\
& Consumable Storage Capability \\
\hline Surface Mobility/HRS & Vehicle Size \\
& Terrain Mobility Capabilities \\
& Tele-operation Requirements \\
& Autonomy Requirements \\
& Power Requirements \\
& Fuel Cell Reagent Quantities \\
& Fuel Cell Reagent Type \\
\hline Surface Power & Daylight Power Amount \\
& Nighttime Power Amount \\
& Fuel Cell Storage Capability \\
& Nuclear Reactor Placement/Shielding \\
\hline Habitat & Placement \\
& Shielding/Protection \\
& Assembly/lnflation Capability \\
\hline
\end{tabular}

\begin{tabular}{|c|c|}
\hline \multicolumn{2}{|c|}{ Hardware Connectivity } \\
\hline Propulsion Systems & $\begin{array}{l}\text { Propellant Storage \& Valving } \\
\text { Solar Collectors/Solar Thermal Propulsion } \\
\text { Consumable Storage \& Valving } \\
\text { Water Processing/Electrolysis } \\
\text { Carbon Dioxide Seperation and Processing } \\
\text { Liquid/Gas Separation } \\
\text { Solar Collectors/Trash Processing }\end{array}$ \\
\hline Surface Mobility/HRS & $\begin{array}{l}\text { Mobility Platforms } \\
\text { Actuators, Motors, \& Control Software }\end{array}$ \\
\hline Surface Power & $\begin{array}{l}\text { Consumable Storage \& Valving } \\
\text { Water Processing/Electrolysis } \\
\text { Liquid/Gas Separation } \\
\text { Solar Collectors/Solar Thermal Power \& Storage }\end{array}$ \\
\hline Science Instruments & $\begin{array}{l}\text { Geotechnical Properties } \\
\text { Mineral Properties } \\
\text { Volatile Characterization } \\
\text { Mobility Platforms }\end{array}$ \\
\hline Testing \& Certification & $\begin{array}{l}\text { Surface Analogs } \\
\text { Environment Simulation Chambers } \\
\text { Lunar Regolith Simulants } \\
\text { Simulant Bed Preparation }\end{array}$ \\
\hline
\end{tabular}




\section{ISRU Insertion Approaches}

- Evolve Sustainability - ISRU When Its Ready (current approach)

- No reusable transportation elements at the start of the architecture

- ISRU \& propellant depots not in initial critical path to mission success

- Demonstrate ISRU capabilities early

- Design Architecture to incorporate ISRU products and services when adequately demonstrated

\section{Low Risk but High Life Cycle Costs}

$>$ Sustainability as Driver - ISRU From Start (this may be the new program)

- Develop reusable transportation elements, propellant depots, and ISRU in critical path; human and cargo landers synergistic with Mars

- Utilize Earth supplied propellants for depot until ISRU is fully demonstrated

Higher Upfront Costs \& Delayed Human Exploration but more Sustainable 